\title{
Pamukkale Üniversitesi Tıp Fakültesi öğrencilerinin tıbbi radyasyon ve radyasyon güvenliği hakkında bilgi düzeyleri
}

\author{
Pamukkale University Faculty of Medicine students' level of knowledge about \\ medical radiation and radiation safety
}

\author{
Vefa Çakmak, Çiğdem Akış, Merve Koç, Betül Güngör, Duygu Tuncel
}

Gönderilme tarihi:26.09.2021

Kabul tarihi:09.02.2022

\section{Öz}

Amaç: Amacımız Pamukkale Üniversitesi Tıp Fakültesi öğrencilerinin, tıbbi radyasyon ve radyasyon güvenliği hakkındaki bilgi düzeylerini değerlendirmektir.

Gereç ve yöntem: Tanımlayıcı nitelikte kesitsel özellikteki bu çalışmada, veriler anket yöntemiyle, Nisan 2021-Temmuz 2021 tarihleri tarihleri arasında elde edilmiştir. Çalışma, pandemi döneminde Pamukkale Üniversitesi Tıp Fakültesi öğrencilerinin gönüllü olarak Google form üzerinden anket sorularını cevaplandırması şeklinde yapılmıştır. Veri toplama formu 24 sorudan oluşmaktaydı. 22 soru katılımcıların radyasyon güvenliği ve radyasyon bilgi düzeylerini değerlendirmeye yönelik hazırlanmıştı.

Bulgular: Çalışma grubunu oluşturan Pamukkale Üniversitesi Tıp Fakültesi öğrencileri ( $n=83$ öğrenci, 62 kadın, 21 erkek) tıp fakültesi öğrenim sürelerine göre iki gruba ayrılmıştır. Görüntüleme yöntemlerinin radyasyon içeriği hakkındaki sorulara çalışma grubu, röntgende $\% 96,4$, Bilgisayarlı Tomografi'de $\% 83,1$, mamografide $\% 66,3$ ve anjiyografide \%44,6 oranında doğru cevap vermiştir. Mamografi ve BT hakkında verilen cevaplarda ileri sınıf öğrencilerin daha başarılı oldukları bulunmuştur. Tıp fakültesi öğrencilerinin veri toplama formuna radyasyon güvenliği hakkında verdikleri cevaplar açısından 1-2. sınıflar ile 3-5. sınıflar arasında anlamlı farklılık saptanmadı. Sonuç: Pandemi döneminde dijitalleşen öğrenim sisteminde, tıp eğitimi müfredatında radyasyon güvenliği hakkındaki ders sayılarının arttırılması, gelecekte tıp fakültesi öğrencilerinin görüntüleme yöntemlerini kullanırken daha duyarlı ve daha güvenli olmalarını sağlayacaktır.

Anahtar kelimeler: Radyasyon, X ışını, röntgen, bilgisayarlı tomografi.

Çakmak V, Akış Ç, Koç M, Güngör B, Tuncel D. Pamukkale Üniversitesi Tıp Fakültesi öğrencilerinin tıbbi radyasyon ve radyasyon güvenliği hakkında bilgi düzeyleri. Pam Tıp Derg 2022;15:461-466.

\begin{abstract}
Purpose: Our aim is to evaluate the knowledge level of Pamukkale University Faculty of Medicine students about medical radiation and radiation safety.

Materials and methods: In the descriptive and cross-sectional study, the data were obtained by survey method between April 2021 and July 2021. The study was conducted in the form of voluntary survey questions answered by Pamukkale University Faculty of Medicine students via the Google form during the pandemic period. The data collection form consisted of 24 questions. 22 questions were prepared to evaluate the radiation safety and radiation knowledge levels of the participants.

Results: Pamukkale University Faculty of Medicine students ( $n=83$ students, 62 females, 21 males), constituting the study group, were divided into two groups according to the duration of their medical school education period. The study group answered the questions about the radiation content of imaging modalities correctly in $96.4 \%$ in X-ray, $83.1 \%$ in Computed Tomography, $66.3 \%$ in mammography and $44.6 \%$ in angiography. It was found that advanced students were more successful in the answers given about mammography and CT. There was no significant difference between 1-2 classes and 3-5 classes in terms of the answers given by the medical faculty students to the data collection form about radiation safety.

Conclusion: Increasing the number of courses on radiation safety in the medical education curriculum in the digitized learning system during the pandemic period will allow medical school students to be more sensitive and safer when using imaging methods in the future.
\end{abstract}

Key words: Radiation, Xrays, roentgen, computed tomography.

Vefa Çakmak, M.D. Pamukkale Üniversitesi Tıp Fakültesi, Radyoloji Anabilim Dalı, Denizli, Türkiye, e-posta: vefacakm@yahoo.com (https:// orcid.org/0000-0001-7002-5594) (Sorumlu Yazar)

Çiğdem Akış, Öğrenci, Pamukkale Üniversitesi Tıp Fakültesi, 3. Dönem öğrencisi, Denizli, Türkiye, e-posta: cigdemakis15@gmail.com (https:// orcid.org/0000-0003-0586-4476)

Merve Koç, Öğrenci, Pamukkale Üniversitesi Tıp Fakültesi, 3. Dönem öğrencisi, Denizli, Türkiye, e-posta: mervekoocc7@gmail.com (https:// orcid.org/0000-0003-1148-0313)

Betül Güngör, Öğrenci, Pamukkale Üniversitesi Tıp Fakültesi, 4. Dönem öğrencisi, Denizli, Türkiye, e-posta: bbtlgngr@gmail.com (https://orcid. org/0000-0002-8648-280X)

Duygu Tuncel, Öğrenci, Pamukkale Üniversitesi Tıp Fakültesi, 3. Dönem öğrencisi, Denizli, Türkiye, e-posta: duygutncl@gmail.com (https:// orcid.org/0000-0002-8013-0619) 
Cakmak V, Akis C, Koc M, Gungor B, Tuncel D. Pamukkale University Faculty of Medicine students' level of knowledge about medical radiation and radiation safety. Pam Med J 2022;15:461-466.

\section{Giriş}

Tanı ve tedavi amacıyla kullanılan radyasyon içeren tıbbi görüntüleme yöntemlerinin insan sağlığına zararlı etkileri bulunmaktadır. Çalışan sağlık personelinin radyasyondan korunması için Temel Güvenlik prensibi radyasyona maruziyetin minimum zaman, maksimum uzaklık ve doğru zırhlama ile sınırlandırılmasıdır. Radyasyondan korunma ile radyasyon güvenliği eğitimi Tıp fakültelerinin öğrenim planlarında bulunmakta ve ders olarak tıp fakültesi öğrencilerine verilmektedir. Tıp fakültesi öğrencilerinin radyasyon içeren görüntüleme yöntemleri ile karşılaşmaları ilk olarak 4. sınıfta gerçekleşmektedir.

Bilgisayarlı Tomografi (BT) acil servislerde klinik pratikte ikinci sıklıkta kullanılan radyasyon içeren görüntüleme yöntemlerindendir. BT cihazlarındaki teknolojik gelişmeler ve tanısal performansı artışı ile eş olarak acil servislerde BT kullanımını çok arttırmıştır [1]. Ayrıca tecrübenin artışı ile BT kullanımı azalmaktadır [2]. Yapılan araştırmalarda radyasyon ve radyasyon güvenliği hakkında hekimlerin bilgilerinin yetersiz olduğu bildirilmektedir [3, 4]. Öğrenimin dijitalleştiği pandemi döneminde, hekim adaylarının mezuniyet sonrası tanısal doğruluklarının arttırıması amacıyla BT kullanımında belirgin artış beklenmekte ve hekim adaylarının radyasyondan korunma hakkında alacağı eğitimin önemi artmaktadır. $\mathrm{Bu}$ çalışmanın amacı pandemi döneminde Tıp Fakültesi öğrencilerinin tıbbi radyasyon ve radyasyon güvenliği hakkındaki bilgi düzeylerini değerlendirmektir.

\section{Gereç ve yöntem}

Çalışma öncesinde, Pamukkale Üniversitesi Tıp Fakültesi, Girişimsel Olmayan Klinik Araştırmalar Etik Kurulu'ndan onay alınmıştır. Çalışma tanımlayıcı nitelikte kesitsel özelliktedir. Araştırmadaverileranketyöntemiyle, 07.04.2021 ve 16.07.2021 tarihleri arasında elde edilmiştir. Çalışma, pandemi döneminde Pamukkale Üniversitesi Tıp Fakültesi öğrencilerinin gönüllü olarak Google form üzerinden anket sorularını cevaplandırması şeklinde yapıldı. Veri toplama formu 24 sorudan oluşmaktadır. Formun ilk iki sorusu katılımcıların hangi dönemde olduklarını ve cinsiyetlerini değerlendirmeye yönelikti. Kalan 22 soru ise katılımcıların radyasyon güvenliği ve radyasyon bilgi düzeylerini değerlendirmeye yönelik hazırlanmıştı. Veri toplama formuna, bu konu hakkında tıp fakültesi öğrencileri tarafından yapılan önerilerde kaydedildi. Yapılan anketten elde edilen veriler Google Form vasıtası ile kaydedildi. Veri analizi, istatistiksel yazılım (SPSS 21 for Windows, Chicago, IL) kullanılarak kişisel bilgisayarda gerçekleştirilmiştir. Tanımlayıcı istatistikler, sürekli değişkenlerde ortalama \pm standart sapma, kategorik değişkenlerde ise \% olarak gösterildi. Kategorik değişkenler için kikare testi kullanıldı. $P<0,05$ istatistiksel olarak anlamlı kabul edildi.

\section{Bulgular}

Ankete katılan Pamukkale Üniversitesi Tıp Fakültesi öğrencileri ( $n=83$ öğrenci, 62 kadın, 21 erkek) tıp fakültesi öğrenim süresinin büyük kısmı online/dijital olanlar (1. ve 2. sınıflar, $\mathrm{n}=46$ öğrenci) ile öğrenim süresinin daha $a z$ kısmı online/dijital olanlar (3, 4 ve 5. sınıflar, $\mathrm{n}=37$ ) olarak iki gruba ayrılmıştır. Çalışma grubunda hastanelerde kullanılan radyolojik görüntüleme yöntemlerinin radyasyon kullanımı hakkında verilen cevaplar Tablo 1'de ve veri toplama formuna radyasyon güvenliği ve radyasyon hakkında verilen cevaplar Tablo 2'de sunulmuştur.

1-2. sınıfların radyasyon güvenliği ile ilgili sorulara verdikleri cevaplar $\% 4,3-\% 97,8,3-5$. sınıfların radyasyon güvenliği ile ilgili sorulara verdikleri cevaplar ise $\% 13,5-\% 97,3$ bulundu. Tıp fakültesi öğrencilerinin veri toplama formuna radyasyon güvenliği ve radyasyon hakkında verdikleri cevaplar açısından 1-2. sınıflar ile 3-5. sınıflar arasında anlamlı farklılık saptanmadı. Çalışma grubunun sadece \%9,6'sı radyasyon hakkında yeterli bilgiye sahip olduğunu belirtirken, çalışma grubunun \%84,3'ünün radyasyon güvenliği hakkında eğitimin verilmesi gerektiğini bildirmişlerdir. 
Tablo 1. Çalışma grubundaki tıp fakültesi öğrencilerinin görüntüleme yöntemlerinin radyasyon içermesi hakkındaki cevapları

\begin{tabular}{llllll}
\hline \multirow{2}{*}{ Görüntüleme modaliteleri } & Dönem & Var (\%) & Yok (\%) & Bilmiyorum (\%) & $\boldsymbol{p}$ \\
\hline Röntgen & $1-2$ & $45(97,8)$ & 0 & $1(2,2)$ & 0,258 \\
& $3-5$ & $35(94,6)$ & $2(5,4)$ & 0 & \\
BT & $1-2$ & $40(87)$ & 0 & $6(13)$ & $\mathbf{0 , 0 4 5}$ \\
Mamografi & $3-5$ & $36(97,3)$ & $1(2,7)$ & 0 & $\mathbf{0 , 0 0 5}$ \\
& $1-2$ & $25(54,3)$ & $4(8,7)$ & $17(37)$ & \\
MR & $3-5$ & $30(81,1)$ & $3(8,1)$ & $4(10,8)$ & 0,387 \\
& $1-2$ & $12(26,1)$ & $31(67,4)$ & $3(6,5)$ & \\
Anjiyografi & $3-5$ & $4(10,8)$ & $33(89,2)$ & 0 & 0,254 \\
& $1-2$ & $17(37)$ & $13(28,3)$ & $16(34,8)$ & \\
PET/BT & $3-5$ & $20(54,1)$ & $6(16,2)$ & $11(29,7)$ & 0,187 \\
& $1-2$ & $32(69,6)$ & $2(4,3)$ & $12(26,1)$ & \\
\hline BT: Bilgisayarlı Tomografi, MR: Manyetik Rezonans, PET: Pozitron Emisyon Tomografi & &
\end{tabular}

Tablo 2. Çalışma grubundaki tıp fakültesi öğrencilerinin veri toplama formuna radyasyon güvenliği ve radyasyon hakkındaki cevapları

\begin{tabular}{|c|c|c|c|c|}
\hline & & $\begin{array}{l}\text { Evet } \\
(\%)\end{array}$ & $\begin{array}{l}\text { Hayır } \\
(\%)\end{array}$ & $\begin{array}{l}\text { Bimiyorum } \\
(\%)\end{array}$ \\
\hline \multirow[t]{7}{*}{ Grup A } & $\begin{array}{l}\text { İyonize radyasyonun en çok etkilediği doku sinir sistemi ve kas } \\
\text { dokudur }\end{array}$ & $41(49,4)$ & $7(8,4)$ & $35(42,2)$ \\
\hline & Çocuklar erişkinlere göre radyasyondan daha fazla etkilenir & $60(72,3)$ & $2(2,4)$ & $21(25,3)$ \\
\hline & Gebelikte fetüs radyasyona duyarlı mıdır? & $81(97,6)$ & $2(2,4)$ & 0 \\
\hline & Radyasyonun etkisi maruz kalınan süreye ve doza bağlı mıdır? & $80(96,4)$ & $1(1,2)$ & $2(2,4)$ \\
\hline & Radyasyon kaynağından uzaklaştıkça radyasyon dozu düşer mi? & $56(67,5)$ & $7(8,4)$ & $20(24,1)$ \\
\hline & Kısa aralıklarla mamografi çektirmek meme kanseri riskini arttırır mı? & $29(34,9)$ & $19(22,9)$ & $35(42,2)$ \\
\hline & Tıbbi Radyasyona maruziyet (röntgen gibi) kısırlık yapar mı? & $34(41)$ & $19(22,9)$ & $30(36,1)$ \\
\hline \multirow[t]{3}{*}{ Grup B } & $\begin{array}{l}\text { Radyasyon alanlarının kapıları açık kaldığında dışarıdakiler de } \\
\text { aynı oranda radyasyona maruz kalır mı? }\end{array}$ & $22(26,5)$ & $36(43,4)$ & $25(30,1)$ \\
\hline & $\begin{array}{l}\text { Radyasyon ile çalışan sağlık personeli için geçilmemesi gereken bir } \\
\text { etkin doz sınırı var mıdır? }\end{array}$ & $76(91,6)$ & $2(2,4)$ & $5(6)$ \\
\hline & $\begin{array}{l}\text { Anjiyografide floroskopi kullanımı sırasında tiroid koruyucu, gözlük ve } \\
\text { kurşun önlük gibi kişisel koruyucu ekipman kullanılmalı mı? }\end{array}$ & $57(68,7)$ & $4(4,8)$ & $22(26,5)$ \\
\hline \multirow[t]{3}{*}{ Grup C } & $\begin{array}{l}\text { Tıbbi radyasyonda radyasyon dozunu düşürecek telefon uygulaması } \\
\text { ya da yazııı var mı? }\end{array}$ & $4(4,8)$ & $18(21,7)$ & $61(73,5)$ \\
\hline & $\begin{array}{l}\text { Tıbbi ışınlama sonrası süt içmek ya da yoğurt yemek fayda sağlar } \\
\text { mı? }\end{array}$ & $19(22,9)$ & $13(15,7)$ & $51(61,4)$ \\
\hline & Kaktüs tıbbi radyasyondaki ışınlardan korur mu? & $23(27,7)$ & $21(25,3)$ & $39(47)$ \\
\hline \multirow[t]{2}{*}{ Grup D } & $\begin{array}{l}\text { Tıpta kullanılan iyonizan radyasyon ve radyasyonun zararları } \\
\text { hakkında yeterli bilgiye sahibim? }\end{array}$ & $8(9,6)$ & $52(62,7)$ & $23(27,7)$ \\
\hline & $\begin{array}{l}\text { Tıpta kullanılan iyonizan radyasyon ve radyasyonun zararları } \\
\text { hakkında derslerin olmasını isterim? }\end{array}$ & $70(84,3)$ & $3(3,6)$ & $10(12)$ \\
\hline
\end{tabular}


Katılımcıların çalışmada belirtilen radyolojik tetkikler ile ilgili ilgilerinin nereden edindiklerini sorguladığımız soruya; öğrencilerin \%51,8‘i tıp eğitimi yanıtı verirken, \%15,7‘si tıbbi tecrübe/hastane'de edindiklerini, \%12'si aile/ arkadaşlarından, \%13,3'ü medya/sosyal medya aracılığı ile \%7,2'side diğer kaynaklardan edindiğini belirtmiştir (Resim 1).

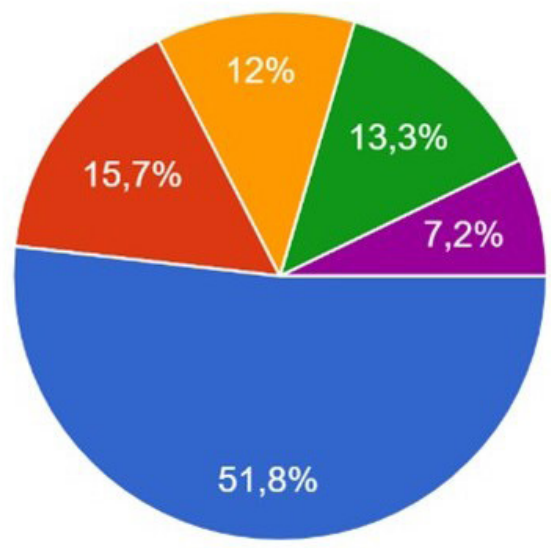

Tıp eğitimi
Tıbbi tecrübem/ Hastane
Ailem/Arkadaşlarım
Medya/Sosyal medya
Diğer

Resim 1. Radyasyon hakkındaki bilgilerimi nereden edindim sorusuna verilen cevapların oranı

\section{Tartışma}

Tıbbigörüntülemedekullanılanradyasyondan korunma, radyasyon güvenliği ve radyasyon hakkındaki bilgi düzeylerinin hastalar ve sağlık çalışanları arasında düşük olduğu bildirilmiştir [5-8]. Madrigano ve ark. [9] çalışmalarında tıbbi görüntüleme yöntemlerinin radyasyon içeriği hakkındaki sorulara röntgende \%95, BT'de $\% 100$, mamografide \%84,2, anjiyografide $\% 80,8$ ve PET/BT'de \%85 oranında doğru cevap vermişlerdir. Çalışmamızda görüntüleme yöntemlerinin radyasyon içeriği hakkındaki sorulara tüm çalışma grubu, röntgende $\% 96,4$, BT'de \%83,1, mamografide \%66,3, anjiyografide $\% 44,6$ ve PET/BT'de \%75,9 oranında doğru cevap verilmiştir. Çalışmamızda mamografi ve BT hakkında verilen cevaplarda ileri sınıf öğrencilerin daha başarılı oldukları bulunmuştur. Lee ve ark. [10] çalışmasında acil servis doktorlarının \%9'unun ve radyologların \%47'sinin BT'deki radyasyonun yaşam boyu kanser riskini arttırdığını düşündüğünü bildirmişlerdir. Biz çalışmamızda kanser gelişimi hakkında öğrencilere sorduğumuz 'Kısa aralıklarla mamografi çektirmek meme kanseri riskini arttırır mı?' sorusuna ise \%34,9 oranında doğru cevap aldık. Koçyiğit ve ark. [11] çalışmasında ise radyolojik tetkikler içinde manyetik rezonansın (MR) ve ultrasonun radyasyon içerdiğini düşünenlerin oranı sırasıyla \%38 ve \%19,6 olarak bildirilmiştir. Çalışmamızda tıp öğrencileri \%77,1 oranında MR'ın radyasyon içermediğini belirtmişlerdir. Çalışmamızın veri toplama formunda ise ultrason hakkında soru bulunmamakta idi.

Radyasyondan korunmada zaman, mesafe ve zırhlama olarak bilinen 3 temel ilke bulunmaktadır. Zırhlama (kurşun blok, kurşun önlük, beton blok vb.) radyoloji klinikleri ve hastanelerde zorunlulukla kullanılan en pratik korunma yöntemidir. Mesafe ise radyasyon dozu ile ters orantılıdır. Kaynaktan uzaklaşma ile doz azalmaktadır. Radyasyon kullanılan cihaz ya da ortamda geçirilen zamanın kısa olması da radyasyondan korunmada önemli yer tutmaktadır. Mesafe ile ilgili 'Radyasyon kaynağından uzaklaştıkça radyasyon dozu düşer mi?' sorusuna da \%67,5 oranında doğru cevap verilmiştir. Çalışmamızda koruyucu ekipman kullanımı hakkında olan soruya verilen cevap ise \%68,7 oranında doğru bulundu.

Radyasyon içeren tıbbi görüntüleme kullanılan kliniklerde ALARA (As Low As Reasonably, Achievable/mümkün olduğunca az) prensibi benimsenmiş olup, hastanın ve sağlık personelinin alabileceği en az dozu alması hakkındadır [12]. Gereksiz radyolojik incelemeler hastalar ve sağlık çalışanları açısından radyasyona maruziyeti arttırmaktadır. Bu nedenle tıp fakülteleri ve sağlık çalışanları için radyasyon güvenliği ve radyasyon hakkında eğitimlerin arttırılması radyasyona maruziyetin 
düşürülmesine önemli katkı sunacaktır [7, 13, 14]. Bizim çalışmamızda çalışma grubundaki tıp öğrencileri Tıpta kullanılan iyonizan radyasyon ve radyasyonun zararları hakkında derslerin olmasını isterim? Sorusuna $\% 84,3$ oranında evet cevabı vermişlerdir. Ayrıca Veri Toplama Formuna, bu konu hakkında yapılan önerilerin büyükkısmıda radyasyon güvenliği ve radyasyon hakkındaki eğitimlerin arttırılması yönündeydi. Yeni mezun hekimlerin sıklıkla atanıp çalıştığı Acil servislerde hasta yoğunluğuna ve sıklıkla gelişen panik durumuna bağlı olarak hekim ve sağlık çalışanlarının tanısal performanslarının artması amacıyla çok sayıda radyolojik inceleme yapılmaktadır. Güzel ve ark. [4] çalışmasında acil servislerde gereksiz radyolojik incelemelerin ve bu incelemelere ait maliyetlerin azaltılması için periyodik eğitim programlarının uygulanması gerektiği bildirilmiştir. Schuster ve ark. [15] ise çalışmalarında son yıllarda hastaların radyasyon bilgi düzeylerinin artığını bildirmişlerdir. Bu artışın sebebi olarak; radyasyon güvenliği hakkında birçok çalışmanın yapıldığını, sağlık çalışanlarına iyonize radyasyon ve riskleri konusunda eğitimler verilmesi gösterilmiştir.

Radyasyonun deterministik ve stokastik olarak sınıflanmış iki biyolojik etki mekanizması bulunmaktadır. Radyasyonun deterministik etkisine yüksek dozlara maruz kalınmasıyla doğrudan hücresel ölüm), cilt yanıkları, sterilite veya katarakt oluşumu örnek verilebilir. Stokastik etkisine ise radyasyona maruziyetten uzun süreler sonra ortaya çıkan mutasyon veya kanser gelişimi örnek verilebilir. Herhangi bir radyasyon dozunun mutasyon ya da kanser gelişimine neden olabileceği bildirilmiştir [16]. Radyasyonun canlılar üzerinde olumsuz biyolojik etkilerine rağmen, hastalıkların tanı ve tedavisinde radyasyon kullanılan tıbbi görüntüleme yöntemleri önemlidir. Günümüzde artan teknoloji ve tanısal performansları arttırma endişeleri nedeniyle hastanelerde ve acil servislerde BT kullanımı artmaktadır [1, 17].

Ceylan ve ark. [18] çalışmalarında hastaların radyasyonun zararlı etkileri hakkındaki bilgi düzeyini değerlendirmişlerdir. Çalışma grubundaki hastaların \%49,7'sinin bilgi almadığı, $\% 50,3$ 'ün ise basın yayın organlarından bilgi aldığını bildirmişlerdir. Çalışmamızda ise radyasyonun zararlı etkileri hakkındaki bilgileri tıp öğrencilerinin \%67,5'inin tıp eğitiminden/ hastaneden aldığı, geri kalan grupta ise \%13,3'lük kısmın ise sosyal medya/internetten bilgilendiği saptanmıştır.

Çalışma grubundaki tıp öğrencilerinin bu konu hakkındaki sosyal medya ve benzeri platformlardan ya da değişmemiş eski yönetmelikten öğrenebilecekleri yanlış bilgileri ölçmek amacıyla da anketimize üç farkı soru eklendi. Kaktüsün tıbbi radyasyondaki ışınlardan bizi koruyup korumadığına \%27,7 oranında, tıbbi ışınlama sonrası süt içmenin ya da yoğurt yemenin herhangi bir fayda sağlayıp sağlamadığını sorduğumuz soruda $\% 22,9$ ve radyasyon dozunu düşürecek bir uygulama ya da yazılım biliyor musunuz sorusuna da $\% 4,8$ oranında evet cevabı verildi. Bu cevaplara bağıı olarak tıp fakülteleri öğrencilerine pandemi sonrası dönemde daha fazla yararını görecekleri ve doğruları öğrenecekleri radyasyondan korunma hakkında derslerinde birkaç dönemde tekrar edilmesini önermekteyiz.

Çalışmamızın bazı kısıtıııkları vardı. Birincisi çalışma grubu olan tıp fakültesi öğrencilerinin anket formunu cevaplama sayılarının, sınıf mevcutlarına göre az olmasıydı. Bunun nedeninin öğrenim sisteminin dijitalleşmesiyle çok fazla anket formu şeklinde çalışmaya cevap vermeyi reddetmeleri olarak düşünmekteyiz. İkinci kısıtııı̆ımız, bazı tıp öğrencilerin pandemi döneminde öğrenim sürelerinin ve konsantrasyonlarının düşmesine bağlı anketin doldurulmasını reddetmeleri idi. Bu çalışma grubumuzun sayısının düşük olmasının önemli bir nedeni idi. Ayrıca ileri dönem sınıf öğrencilerinin katıımının düşük olması da çalışmanın önemli bir kısıtlıı̆ğı idi.

Sonuç olarak, pandemi döneminde dijitalleşen öğrenim sisteminde, radyasyon güvenliği ile radyasyon hakkında tıp eğitimi müfredatındaki ders sayılarının artıııması gerekmektedir. Bu eğitim özellikle tecrübesiz hekimlerin radyasyon içeren görüntüleme yöntemlerini kullanırken daha duyarlı ve daha güvenli yaklaşımlarını sağlayacaktır.

Çıkar ilişkisi: Yazarlar çıkar ilişkisi olmadığını beyan eder.

\section{Kaynaklar}

1. Larson DB, Johnson LW, Schnell BM, Salisbury SR, Forman HP. National trends in CT use in the emergency department: 1995-2007. Radiology 2011;258:164-173. https://doi.org/10.1148/radiol.10100640 
2. Kirsch TD, Hsieh YH, Horana L, Holtzclaw SG, Silverman M, Chanmugam A. Computed tomography scan utilization in emergency departments: a multistate analysis. J Emerg Med 2011;41:302-309. https:// doi.org/10.1016/j.jemermed.2010.06.030

3. Shiralkar S, Rennie A, Snow M, Galland RB, Lewis $\mathrm{MH}$, Gower Thomas K. Doctors' knowledge of radiation exposure: questionnaire study. BMJ 2003;327:371372. https://doi.org/10.1136/bmj.327.7411.371

4. Güzel A, Temziöz O, Aksu B, Süt N, Karasalihoğlu S. A cost analysis of radiologic imaging in pediatric trauma patients. Ulus Travma Acil Cerrahi Derg 2010;16:313318.

5. Vural F, Fil Ş, Çiftçi S, Aydın Dura A, Yıldııım F, Patan R. Ameliyathanelerde radyasyon güvenliği; çalışan personelin bilgi, tutum ve davranışları. Balıkesir Sağıı Bil Derg 2012;1:131-136.

6. Güden E, Öksüzkaya A, Balcı E, Tuna R, Borlu A, Çetinkara K. Radyoloji çalışanlarının radyasyon güvenliğine ilişkin bilgi, tutum ve davranışı. Sağlıkta Performans ve Kalite Dergisi 2012;3:29-45.

7. Arslanoğlu A, Bilgin S, Kubal Z, Ceyhan MN, Ilhan MN, Maral I. Doctors' and intern doctors' knowledge about patients' ionizing radiation exposure doses during common radiological examinations. Diagn Interv Radiol 2007;13:53-55.

8. Yucel A, Alyesil C, Sim S. Physicians' knowledge about ionizing radiation and radiological imaging techniques: a cross-sectional survey. Acta Radiol 2011;52:537-539. https://doi.org/10.1258/ar.2011.100288

9. Madrigano RR, Abrão KC, Puchnick A, Regacini R. Evaluation of non-radiologist physicians' knowledge on aspects related to ionizing radiation in imaging. Radiol Bras 2014;47:210-216. https://doi.org/10.1590/01003984.2013.1840

10. Lee $\mathrm{Cl}$, Haims AH, Monico EP, Brink JA, Forman HP. Diagnostic CT scans: assessment of patient, physician, and radiologist awareness of radiation dose and possible risks. Radiology 2004;231:393-398. https:// doi.org/10.1148/radiol.2312030767

11. Koçyiğit $A$, Kaya $F$, Çetin $T$, et al. Radyolojik tetkikler sırasında maruz kalınan radyasyon hakkında sağlık personelinin bilgi düzeyleri. Pam Tıp Derg 2014;7:137142.

12. Lurie AG. Doses, benefits, safety, and risks in oral and maxillofacial diagnostic imaging. Health Phys 2019;116:163-169. https://doi.org/10.1097/ HP.0000000000001030

13. Amare DE, Dagne $\mathrm{H}$. Knowledge and associated factors of medical students regarding radiation exposure from common diagnostic imaging procedures at the University of Gondar, Ethiopia. Ethiop J Health Sci 2020;30:589-598. https://doi.org/10.4314/ejhs. v30i4.14
14. Teferi S, Zewdeneh D, Bekele S. Pediatric residents' and medical interns' awareness about pediatric lonizing radiation dose from computed tomography and Its associated risks in tertiary Hospital in Ethiopia. Ethiop J Health Sci 2018;28:383-392. https://doi.org/10.4314/ ejhs.v28i4.4

15. Schuster AL, Forman HP, Strassle PD, Meyer LT, Connelly SV, Lee $\mathrm{Cl}$. Awareness of radiation risks from CT scans among patients and providers and obstacles for informed decision-making. Emerg Radiol 2018;25:41-49. https://doi.org/10.1007/s10140-017$1557-8$

16. Little MP, Wakeford R, Tawn EJ, Bouffler SD, Berrington de Gonzalez A. Risks associated with low doses and low dose rates of ionizing radiation: why linearity may be (almost) the best we can do. Radiology 2009;251:612. https://doi.org/10.1148/radiol.2511081686

17. Roudsari BS, Psoter KJ, Vavilala MS, Mack CD, Jarvik JG. CT use in hospitalized pediatric trauma patients: 15 -year trends in a level I pediatric and adult trauma center. Radiology 2013;267:479-486. https://doi. org/10.1148/radiol.13120865

18. Ceylan I, Er A, Nayır T, Yasılı G, Akman C. Radyolojik tetkik yaptıran hastaların radyasyonun zararlı etkileri hakkında bilgi düzeyleri. Smyrna Tıp Dergisi 2014;2:16.

Etik kurul onayı: Çalışma için, Pamukkale Üniversitesi Girişimsel Olmayan Klinik Araştırmalar Etik Kurulu'ndan 14/07/2021 tarih ve E-60116787-020-77786 sayı ile onay alınmıştır.

\section{Yazarların makaleye olan katkıları}

V.Ç. çalışmanın ana fikrini ve hipotezini kurgulamıştır. V.Ç., Ç.A., M.K., D.T. ve B.G. verileri toplamış, analiz etmiş ve makalenin yazımına katkı sağlamıştır. V.Ç. makaleyi gözden geçirip gerekli düzeltmeleri yapmış ve onaylamıştır. Tüm yazarlar eleştirel geri bildirim sağlayarak ve araştırmanın, analizin ve makalenin şekillenmesine yardımcı olmuştur. 